\title{
Aqueous Extract of Paeonia suffruticosa Inhibits Migration and Metastasis of Renal Cell Carcinoma Cells via Suppressing VEGFR-3 Pathway
}

\author{
Shih-Chin Wang, ${ }^{1}$ Sai-Wen Tang, ${ }^{1}$ Sio-Hong Lam, ${ }^{2}$ Chung-Chieh Wang, ${ }^{3}$ Yu-Huei Liu, ${ }^{1,4,5}$ \\ Hsuan-Yuan Lin, ${ }^{1}$ Shoei-Sheng Lee, ${ }^{2}$ and Jung-Yaw Lin ${ }^{1}$ \\ ${ }^{1}$ Institute of Biochemistry and Molecular Biology, College of Medicine, National Taiwan University, Taipei 10051, Taiwan \\ ${ }^{2}$ School of Pharmacy, College of Medicine, National Taiwan University, Taipei 10051, Taiwan \\ ${ }^{3}$ Department of Pathology, National Taiwan University Hospital, Taipei 10002, Taiwan \\ ${ }^{4}$ Graduate Institute of Integrated Medicine of Chinese Medicine, China Medical University, Taichung, Taiwan \\ ${ }^{5}$ Department of Medical Genetics and Medical Research, China Medical University Hospital, Taichung, Taiwan \\ Correspondence should be addressed to Jung-Yaw Lin, linjy@ntu.edu.tw
}

Received 28 June 2011; Accepted 2 November 2011

Academic Editor: Lixing Lao

Copyright ( $) 2012$ Shih-Chin Wang et al. This is an open access article distributed under the Creative Commons Attribution License, which permits unrestricted use, distribution, and reproduction in any medium, provided the original work is properly cited.

Renal cell carcinoma (RCC) cells are characterized by strong drug resistance and high metastatic incidence. In this study, the effects of ten kinds of Chinese herbs on RCC cell migration and proliferation were examined. Aqueous extract of Paeonia suffruticosa (PSA) exerted strong inhibitory effects on cancer cell migration, mobility, and invasion. The results of mouse xenograft experiments showed that the treatment of PS-A significantly suppressed tumor growth and pulmonary metastasis. We further found that PS-A markedly decreased expression of VEGF receptor-3 (VEGFR-3) and phosphorylation of FAK in RCC cells. Moreover, the activation of Rac-1, a modulator of cytoskeletal dynamics, was remarkably reduced by PS-A. Additionally, PS-A suppressed polymerization of actin filament as demonstrated by confocal microscopy analysis and decreased the ratio of F-actin to G-actin in RCC cells, suggesting that PS-A inhibits RCC cell migration through modulating VEGFR-3/FAK/Rac-1 pathway to disrupt actin filament polymerization. In conclusion, this research elucidates the effects and molecular mechanism for antimigration of PS-A on RCC cells and suggests PS-A to be a therapeutic or adjuvant strategy for the patients with aggressive RCC.

\section{Introduction}

Chinese herb medicines have been discovered to be potential therapies for various diseases, including diabetes mellitus, tumor, and hypertension [1]. Recently, increasing evidence has shown that some of Chinese herb medicines can be applied to improve the efficiency of conventional cancer therapies and reduce the side effects of chemotherapies for human malignancies, such as breast cancer and prostate cancer $[2,3]$.

The root cortex of Paeonia suffruticosa has been widely used as traditional Chinese herb remedy for treating various diseases, including macula, epilepsy, and menstrual disorders [4]. Paeonia suffruticosa was demonstrated to exhibit antiproliferation, anti-inflammation, antiinfection, antihypertention, antidiabetics, and neuroprotective activities [58]. The active compounds have been identified from Paeonia suffruticosa, such as paeonol and paeoniflorin [9-14]. However, the effect and detailed mechanism for antimigration of Paeonia suffruticosa on cancer cells are still unclear.

Renal cell carcinoma (RCC) represents $3 \%$ of all human malignancies worldwide with an increasing incidence [1517]. About $70 \%$ of RCCs have been found to be clear cell subtype [18]. The response of RCC cells to traditional therapies, such as the chemotherapy, hormonal therapy, and radiation therapy is very poor $[19,20]$, and one-fourth of the patients have locally invasive or metastatic RCC [21,22], resulting in a low five-year survival rate of RCC patients. 


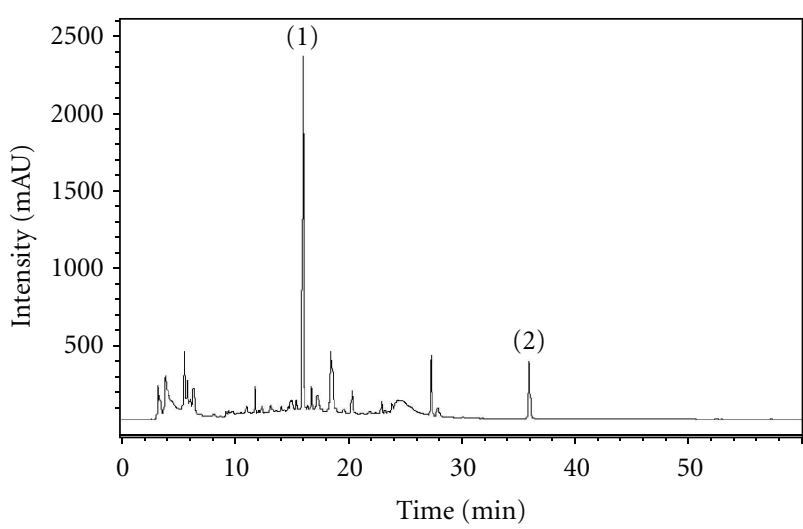

Figure 1: Chemical profile of PS-A by HPLC analysis. Chromatographic patterns of PS-A from HPLC analysis $(230 \mathrm{~nm})$ showed peaks corresponding to the retention times ( $\mathrm{min})$. Paeoniflorin (1) and paeonol (2) were used as reference compounds for Paeonia suffruticosa.

Several immunotherapies have been used for the treatment of metastatic RCC [23], but only small population of patients with advanced RCC show response with a high toxicity [24].

In this study, we examined the antimigration and antiproliferation effects of the aqueous extracts from ten kinds of Chinese herb medicines, including Paeonia suffruticosa, Trichosanthes kirilowii, San jhong kuei jian tang, Taraxacum monogolicum, Kalimeris indica, Platycodi radix, Abrus precatorius, Catharanthus roseus, Andrographis paniculata, and Curcuma zedoaria, and further elucidated the molecular mechanism for the strong antimigration activity of Paeonia suffruticosa to RCC cells.

\section{Materials and Methods}

2.1. Preparation of Chinese Herb Extracts. Aqueous extracts from Paeonia suffruticosa, Trichosanthes kirilowii, San jhong kuei jian tang, Taraxacum monogolicum, Kalimeris indica, Platycodi Radix, Abrus precatorius, Catharanthus roseus, Andrographis paniculata, and Curcuma zedoaria were provided by Sun-Ten Pharmaceutical Company (Taipei, Taiwan). Briefly, one hundred grams of dried Chinese herbs was boiled with $1,500 \mathrm{~mL}$ of $\mathrm{H}_{2} \mathrm{O}$ at $100^{\circ} \mathrm{C}$ for $30 \mathrm{~min}$ and was sieved using a 100 -mesh sieve. The extracts were concentrated to $100 \mathrm{~mL}$ and were filtered through a 200-mesh sieve. The extracts were dried by speed vacuum concentration and then stored at $-20^{\circ} \mathrm{C}$ until used. Furthermore, the chemical profile of aqueous extracts of Paeonia suffruticosa (PS-A) was analyzed by using high-pressure liquid chromatograms (HPLC) and shown in Figure 1. Briefly, HPLC was performed using an Agilent 1100 liquid chromatography (Waldbronn, Germany), consisting of a photodiode array detector. The chromatographic separation of samples $(20 \mu \mathrm{L}$, $20 \mathrm{mg} / \mathrm{mL}$ ) was carried out on a Phenomenex Prodigy ODS3 100A column $(250 \times 4.6 \mathrm{~mm}, 5 \mu \mathrm{m})$, eluted with the mixture of water (A) and acetonitrile (B). The linear gradient program was set as $A-B(v / v)$ from $90: 10$ to $5: 95$ in $60 \mathrm{~min}$ with a flow rate of $0.6 \mathrm{~mL} / \mathrm{min}$. Absorbance was monitored at $230 \mathrm{~nm}$. Paeoniflorin and paeonol were used as reference compounds for Paeonia suffruticosa [10].

2.2. Chemicals and Reagents. Paeonol was purchased from WAKO (Japan) and paeoniflorin was from Sigma (St. Louis, MO). The HPLC-grade acetonitrile was obtained from Mallinckrodt (KY, USA), and deionized water was prepared from a Barnstead water purification system (Dubuque, IA, USA). Alexa568-phalloidin and Hoechst 33258 were from Invitrogen Co. Antibodies against VEGF receptor-3, phospho-FAK (Y397), and Rac-1 were obtained from Santa Cruz Biotechnology Inc. Actin, immobilon Western, and secondary antibodies were purchased from Millipore Co. EDTA-free protease inhibitor cocktail was from Roche Diagnostics.

2.3. Cell Line and Culture. Renal cell carcinoma cell line $786 \mathrm{O}$ was obtained from ATCC and maintained with Dulbecco's Modified Eagle Medium containing 10\% fetal bovine serum, $2 \mathrm{mM}$ L-glutamine, $0.1 \mathrm{mM}$ nonessential amino acids, and $10 \mathrm{U} / \mathrm{mL}$ penicillin/streptomycin at $37^{\circ} \mathrm{C}$ in a $5 \%$ $\mathrm{CO}_{2}$ humidified incubator.

2.4. Cell Proliferation Assay. $786 \mathrm{O}$ cells $\left(7 \times 10^{2}\right.$ cells/well $)$ were seeded into 96-well plates overnight and treated with various concentrations of PS-A for 1-3 days. At the end of treatment, the cells were incubated with $100 \mu \mathrm{L}$ of fresh medium containing $0.5 \mathrm{mg} / \mathrm{mL}$ of 3-[4,5-dimethyl-2-thiazolyl]-2,5-diphenyl-2H-tetrazolium bromide (MTT, Sigma). After incubation for $4 \mathrm{~h}, 100 \mu \mathrm{L}$ of $10 \% \mathrm{SDS} / 0.1 \mathrm{M} \mathrm{HCl}$ was added into well to dissolve the crystal. Absorbance of the reaction products was measured at $590 \mathrm{~nm}$ with a reference wavelength $650 \mathrm{~nm}$.

2.5. Transwell Migration and Invasion Assay. After serum starvation for $24 \mathrm{~h}, 786 \mathrm{O}$ cells $\left(2.5 \times 10^{4}\right.$ cells $)$ were resuspended in $300 \mu \mathrm{L}$ of serum-free medium containing various concentrations of PS-A and then seeded into transwell chambers with or without $40 \mu \mathrm{L}$ of matrigel $(1 \mathrm{mg} / \mathrm{mL}, \mathrm{BD})$ for invasion or migration assay, respectively. The chambers were put into wells of 24-well plates and incubated with $1 \mathrm{~mL}$ of complete medium with $10 \%$ FBS at $37^{\circ} \mathrm{C}$ for $6 \mathrm{~h}$. Cells on the bottom side of the membrane were fixed by $1 \%$ formaldehyde/PBS for $10 \mathrm{~min}$ and stained with $0.2 \%$ crystal violet for $60 \mathrm{~min}$. The migrated or invaded cells were counted using an inverted contrast light microscope under 100x magnification.

2.6. Wound-Healing Assay. $786 \mathrm{O}$ cells were full confluent in 12 -well plates at the time of scrapping. Cells were wound with P200 pipette tips and washed with PBS. Cells were then incubated with fresh complete medium containing various concentrations of PS-A. Photographs were taken at the same position of the wound at 0 and $6 \mathrm{~h}$ after scrapping.

2.7. Mouse Xenograft Model. Four-week-old female NODSCID mice were obtained from the National Laboratory Animal Center. Approval for animal experiments was obtained 
from the Institutional Animal Care and Use Committee of College of Medicine, National Taiwan University. For tumor growth experiments, 7860 cells $\left(2 \times 10^{6}\right.$ cells $)$ were inoculated subcutaneously into the flank of mice. Two days after injection, mice were randomly divided into two groups (4 mice per group) and oral-administrated with water or PSA $(0.29 \mathrm{~g} / \mathrm{kg})$ five times per week. Tumor size was measured with calipers every five day, and mice were sacrificed after 45 days. Tumor volume was evaluated using the formula: $0.52 \times$ $(\text { width })^{2} \times$ length [25]. For tumor metastasis experiments, $786 \mathrm{O}$ cells $\left(2 \times 10^{6}\right.$ cells $)$ were intravenously inoculated to the lateral tail vein. Two days after injection, mice were randomly divided into two groups (4 mice per group), and oraladministrated with water or PS-A $(0.29 \mathrm{~g} / \mathrm{kg})$ five times per week and weighted every five day. Mice were sacrificed after 48 days, and the lungs were excised and fixed by $10 \%$ of formaldehyde. The metastatic nodules of lungs were counted for evaluation of approximating tumor content of lungs.

2.8. Western Blot Analysis. After serum starvation for $24 \mathrm{~h}$, $786 \mathrm{O}$ cells $\left(10^{6}\right.$ cells $)$ were treated with or without $0.3 \mathrm{mg} / \mathrm{mL}$ of PS for $24 \mathrm{~h}$ and then lysed by RIPA buffer ( $50 \mathrm{mM}$ Tris$\mathrm{HCl} \mathrm{pH} 7.5,150 \mathrm{mM} \mathrm{NaCl}, 5 \mathrm{mM}$ EDTA, $1 \%$ Triton X$100,0.1 \%$ SDS, and Roche protease inhibitor cocktail). Fifty $\mu \mathrm{g}$ of protein was resolved on $10 \%$ SDS-polyacrylamide gel and transferred to polyvinylidene fluoride membranes (Millipore, Bedford, MA). The membrane was incubated with primary specific antibodies to VEGFR-3, phosphor-FAK, or actin, followed by horseradish peroxidase-conjugated secondary antibodies (Chemicon International, Temecula, CA). Signals were visualized using enhanced chemiluminescence detection reagent from Millipore. Band intensities were obtained using a UVP BioImaging System (UVP Inc., Upland, CA).

2.9. Rac-1 Activity Assay. 7860 cells were starved for $24 \mathrm{~h}$, treated with or without $0.3 \mathrm{mg} / \mathrm{mL}$ of PS-A for $12 \mathrm{~h}$, and lysed by lysis buffer (50 mM Tris pH 7.6, $150 \mathrm{mM} \mathrm{NaCl}, 1 \%$ Triton X-100, $0.5 \mathrm{mM} \mathrm{MgCl}_{2}$, and Roche protease inhibitor cocktail). $800 \mu \mathrm{g}$ of total lysate was mixed to glutathione beads coupled with the bacterially produced Rac binding domain of Pak (PBD)-GST fusion protein (a gift from Dr. Zee-Fen Chang) by head-to-head rotation at $4^{\circ} \mathrm{C}$ overnight. After centrifugation at $14,000 \mathrm{rpm}$ for $2 \mathrm{~min}$, the GST-PBD beads were washed five times with $500 \mu \mathrm{L}$ of lysis buffer by rotating for $10 \mathrm{~min}$ and then boiled with SDS sample buffer (125 mM Tris-HCl, pH 6.8, 4\% SDS, 5\% $\beta$-mercaptoethanol, $30 \%$ glycerol, and $0.2 \%$ bromophenol blue dye) for $10 \mathrm{~min}$ to release GTP-bound Rac-1 proteins and then subjected to western blot analysis.

2.10. Immunofluorescence Analysis. 7860 cells were seeded on $22 \times 22 \mathrm{~mm}$ cover slides and then treated with fresh medium containing various concentrations of PS-A for $12 \mathrm{~h}$. Cells were washed by PBS and fixed using 4\% formaldehyde/PBS for $10 \mathrm{~min}$. After being permeabilized by $0.25 \%$ Triton X100/PBS, cells were stained by Alexa568-phalloidin and Hoechst 33258 for $15 \mathrm{~min}$. The cover slides were mounted
TABLE 1: Values of $\mathrm{IC}_{50 \text { growth }}$ and $\mathrm{IC}_{50 \text { migration }}$ of Chinese herb extracts at $24 \mathrm{~h}$ for $786 \mathrm{O}$ cells.

\begin{tabular}{lccc}
\hline & $\begin{array}{c}\mathrm{IC}_{50 \text { growth }} \\
(\mathrm{mg} / \mathrm{mL})\end{array}$ & $\begin{array}{c}\mathrm{IC}_{50 \text { migration }} \\
(\mathrm{mg} / \mathrm{mL})\end{array}$ & $\begin{array}{c}\mathrm{IC}_{50 \text { growth }} / \\
\mathrm{IC}_{50 \text { migration }}\end{array}$ \\
\hline Paeonia suffruticosa & 1.5 & 0.3 & 5.0 \\
Trichosanthes kirilowii & 30.0 & 6.2 & 4.8 \\
San jhong kuei jian tang & 22.4 & 9.8 & 2.3 \\
Taraxacum monogolicum & 3.8 & 2.3 & 1.7 \\
Kalimeris indica & 4.8 & 3.7 & 1.3 \\
Platycodi radix & 2.1 & 1.7 & 1.2 \\
Abrus precatorius & 5.9 & - & - \\
Catharanthus roseus & 25.1 & - & - \\
Andrographis paniculata & - & - & - \\
Curcuma zedoaria & - & - & - \\
\hline
\end{tabular}

in $80 \%$ glycerol and sealed with nail polish. The images were analyzed with a Leica TCS SP5 Spectral Confocal System.

2.11. Preparation of F- and G-Actin Fractions. F-actin was separated from G-actin as described previously with some modifications [26]. Briefly, 7860 cells $\left(2 \times 10^{5}\right.$ cells $)$ were treated with $0.3 \mathrm{mg} / \mathrm{mL}$ of PS-A for $12 \mathrm{~h}$ and then incubated with $200 \mu \mathrm{L}$ actin stabilizing buffer (1\% Triton X-100, $1 \mu \mathrm{g} / \mathrm{mL}$ phalloidin and Roche protease inhibitor cocktail) at room temperature for $5 \mathrm{~min}$. The lysate was collected, and F-actin was separated from G-actin by centrifuging at $100,000 \times \mathrm{g}$ at $37^{\circ} \mathrm{C}$ for $1 \mathrm{~h}$. The supernatant was G-actincontaining fraction, and the pellet containing F-actin was washed by PBS twice and dissolved by $200 \mu \mathrm{L}$ of actin dissolving buffer (1\% Triton X-100, 2\% SDS and protease inhibitor cocktail) on ice for $1 \mathrm{~h}$. The F-actin and G-actin fractions were then analyzed by western blotting. The intensity of band in each lane was determined with a Gel-Pro analyzer (Media Cybernetics, GA, USA).

\section{Results}

3.1. Aqueous Extracts of Paeonia suffruticosa Suppresses RCC Cell Migration. To identify active Chinese herb medicines to suppress metastatic process of RCC, aqueous extracts of ten kinds of Chinese herb medicines were prepared for treating $786 \mathrm{O}$ cells, the aggressive RCC cell line. The results of MTT assay and transwell migration assay revealed that aqueous extracts of Paeonia suffruticosa (PS-A) showed a higher inhibitory effect on cancer cell growth $\left(\mathrm{IC}_{50}\right.$ growth $=$ $1.5 \mathrm{mg} / \mathrm{mL}$ ) and a higher ratio between inhibitory effects on cancer cell proliferation and migration in 7860 cells $\left(\mathrm{IC}_{50}\right.$ growth $/ \mathrm{IC}_{50}$ migration $\left.=5.0\right)$, whereas the other nine $\mathrm{CHMs}$ showed lower or no inhibitory effects on cell migration activity (Table 1, Figures 2(a) and 2(b)). Additionally, cell mobility and invasion activities of 7860 cells were strongly suppressed by the treatment of PS-A (Figures 2(c) and $2(\mathrm{~d}))$. These results suggest that PS-A has strong anticancer activities to RCC cells. 


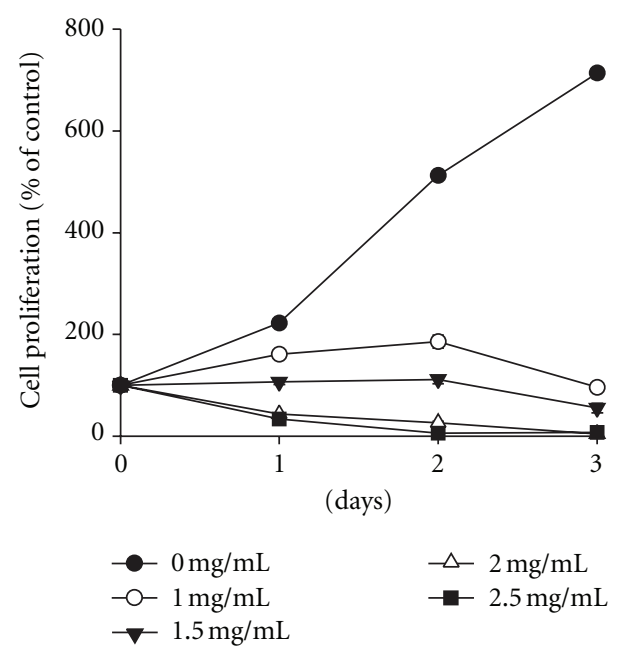

(a)

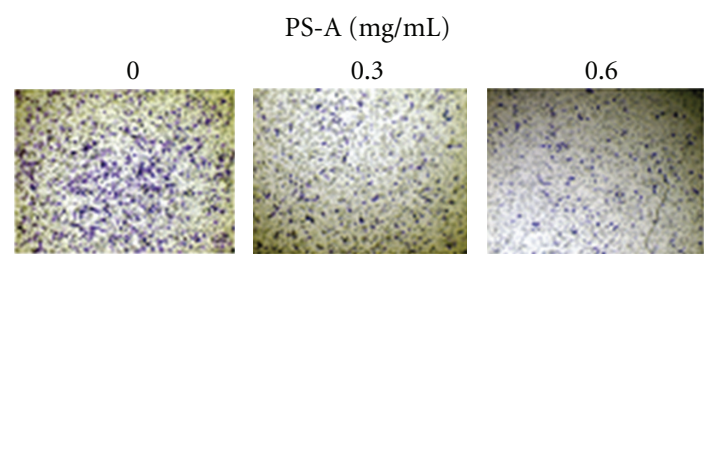

(b)

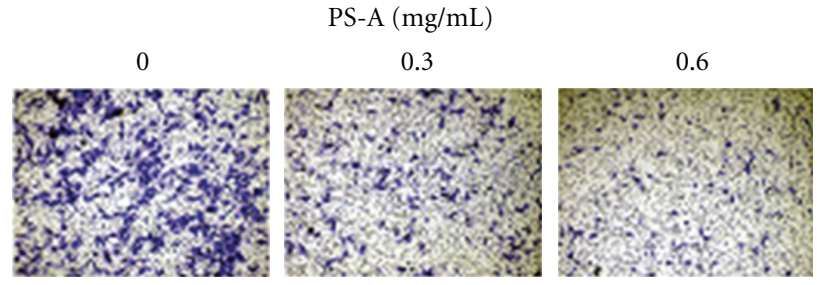

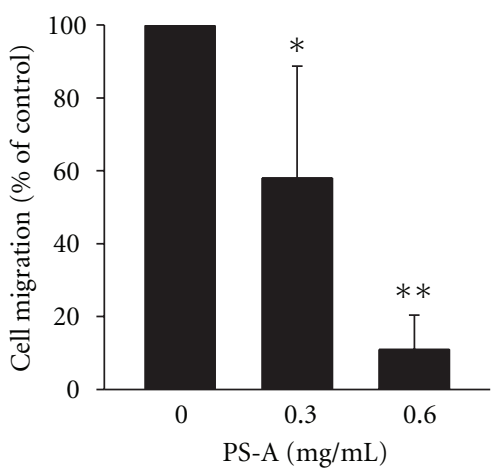

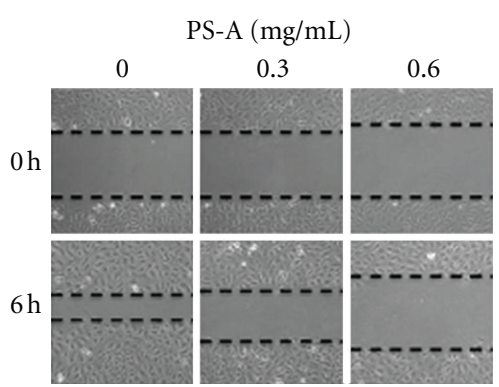

(c)

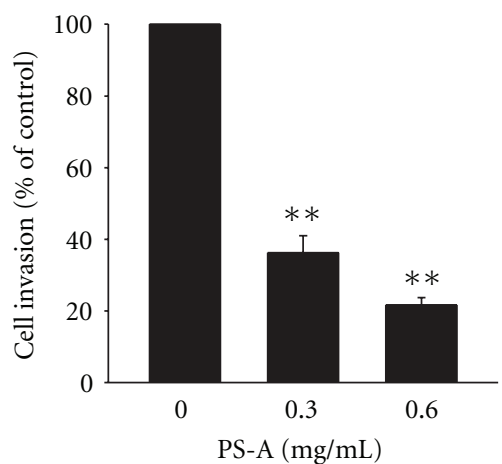

(d)

FIgURE 2: Anticancer effects of PS-A on RCC cells. (a) $7 \times 10^{2}$ of $786 \mathrm{O}$ cells were treated with various concentrations of PS-A for 1,2 , and 3 days. The rate of cell proliferation was measured by MTT assay. The data are represented as the means \pm SD $(n=5)$. (b) $2.5 \times 10^{4}$ of $786 \mathrm{O}$ cells were seeded in transwell chambers and incubated in serum-free medium containing $0,0.3$, and $0.6 \mathrm{mg} / \mathrm{mL}$ of PS-A for $12 \mathrm{~h}$. The migrated cells on the bottom of transwell chambers were fixed and then stained. The migratory activity was determined by counting migrated cells in three microscopic fields. The data are represented as the means $\pm \mathrm{SD}(n=3)$. ${ }^{*} P<0.05 ;{ }^{* *} P<0.001$ compared with untreated cells. (c) Fully confluent $786 \mathrm{O}$ cells were scrapped by P200 pipette tips and then treated with $0,0.3$, and $0.6 \mathrm{mg} / \mathrm{mL}$ of PS-A. Images were taken at 0 and $6 \mathrm{~h}$ after scrapping under 100x magnification. (d) $2.5 \times 10^{4}$ of $786 \mathrm{O}$ cells were seeded in matrigel-coated chambers and then incubated in serum-free medium containing $0,0.3$, and $0.6 \mathrm{mg} / \mathrm{mL}$ of PS-A for $18 \mathrm{~h}$. The invaded cells were fixed and then stained. The invasive activity was determined by counting invaded cells in three microscopic fields. The data are represented as the means \pm SD $(n=3)$. ${ }^{*} P<0.05 ;{ }^{*} P<0.001$ compared with untreated cells. 


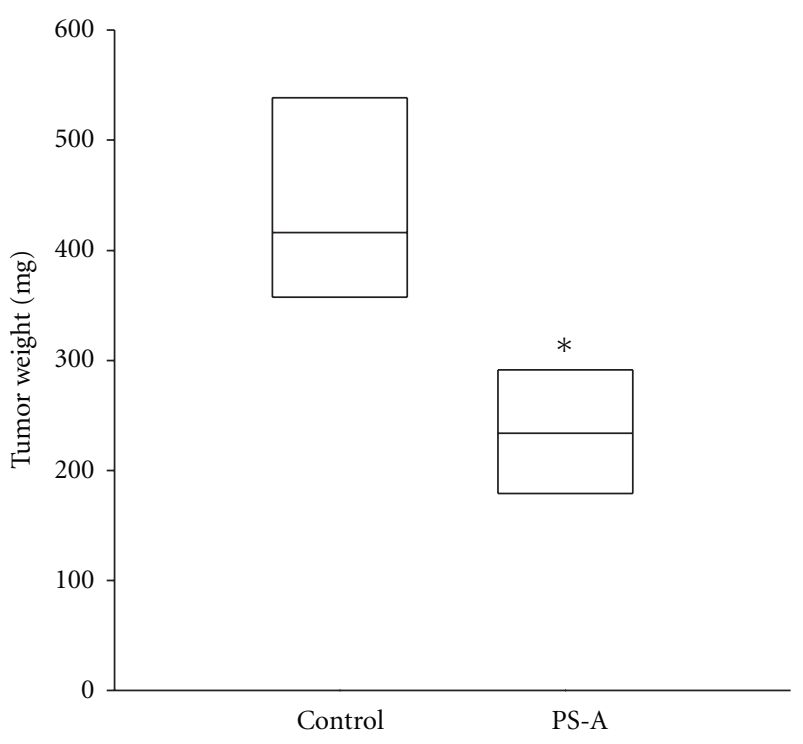

(a)

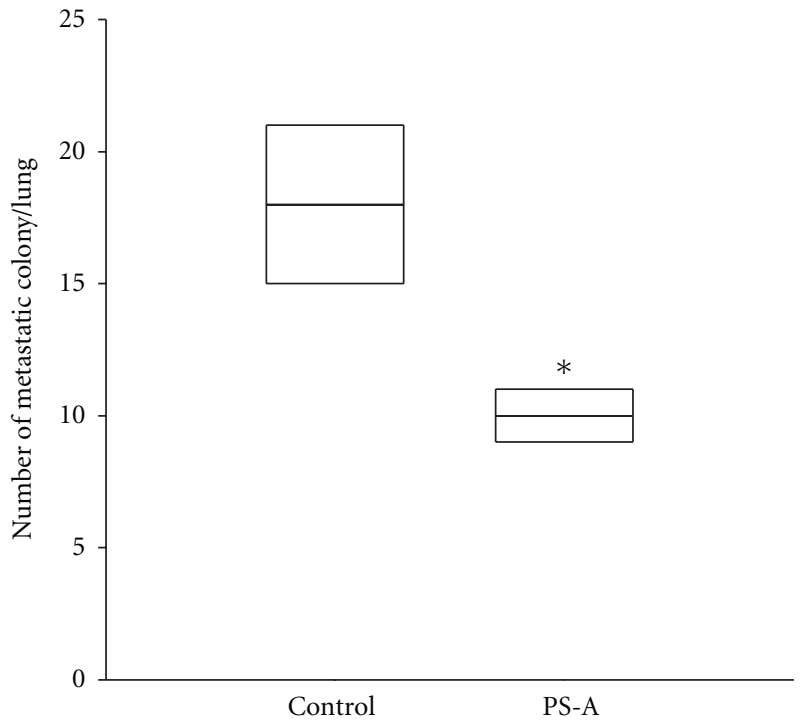

(b)

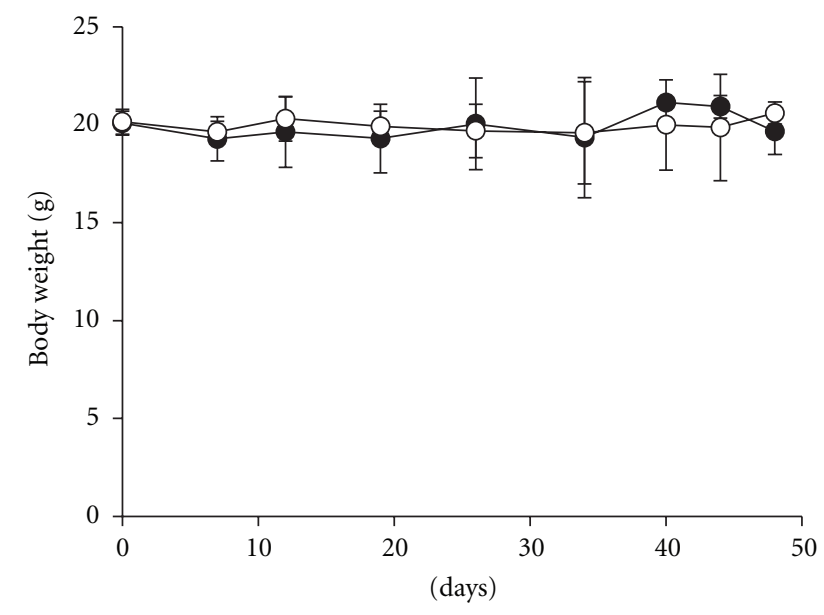

(c)

FIGURE 3: Inhibition of PS-A on tumor growth and metastasis in vivo. (a) $2 \times 10^{6}$ of $786 \mathrm{O}$ cells were inoculated s.c. into the flank of NODSCID mice $(n=4)$. Mice were oral-administrated with water or PS-A $(0.29 \mathrm{~g} / \mathrm{kg})$ for five days per week. After 45 days, mice were sacrificed and tumors were excised. The weights of tumors are represented as the means $\pm \mathrm{SD}(n=4) . * P<0.05$ compared with control. (b) $2 \times 10^{6}$ of $786 \mathrm{O}$ cells were inoculated i.v. into the tail vein of NOD-SCID mice $(n=4)$. Mice were oral-administrated with water or PS $(0.29 \mathrm{~g} / \mathrm{kg})$ for five days per week. After 48 days, mice were sacrificed, and number of metastatic nodules of lung was counted. The number of nodules is represented as the means $\pm \mathrm{SD}(n=4) .{ }^{*} P<0.05$ compared with control. (c) Body weight of mice oral-administrated with water or PS-A $(0.29 \mathrm{~g} / \mathrm{kg})$ for five days per week. Data are represented as the means $\pm \mathrm{SD}(n=4)$.

3.2. PS-A Inhibits Tumor Growth and Metastasis In Vivo. To investigate the effects of PS-A on tumor growth in vivo, 2 $\times 10^{6}$ of $786 \mathrm{O}$ cells were injected subcutaneously into the hind limb of NOD-SCID mice, and then the mice were oraladministrated with water or PS-A $(0.29 \mathrm{~g} / \mathrm{kg})$ five days per week for 45 days. As shown in Figure 3(a), tumor weight of PS-A-treated mice was remarkably lower than that of control group (234.8 mg versus $437.5 \mathrm{mg}$, resp.; $P<0.05$ ). Moreover, $2 \times 10^{6}$ of 7860 cells were i.v. injected into lateral tail vein of NOD-SCID mice to examine the effects of PS-A $(0.29 \mathrm{~g} / \mathrm{kg})$ on the metastatic activity of cancer cells. After 48 days, the number of pulmonary nodules in PS-treated mice was significantly lower than that of untreated group $(10 \pm 1.2$ versus $18.0 \pm 3.3$ nodules/lung, resp.; $P<0.01$; Figure 3(b)). Additionally, feeding of PS-A $(0.29 \mathrm{~g} / \mathrm{kg})$ for 48 days had no significant effect on body weight of mice, suggesting that PS-A showed a very low toxicity to NOD-SCID mice (Figure 3(c)). These results indicate that PS-A inhibits tumor growth and pulmonary metastasis of RCC cells significantly.

3.3. PS-A Represses VEGFR-3/FAK/Rac-1 Signaling Pathway. To explore the mechanism for the anticancer activities of PS-A, we examined the effect of PS-A on VEGFRs, which play an important role in tumor cell growth and metastasis [27]. The results revealed that the expression of VEGFR3 was markedly inhibited by treating 7860 cells with PS-A 


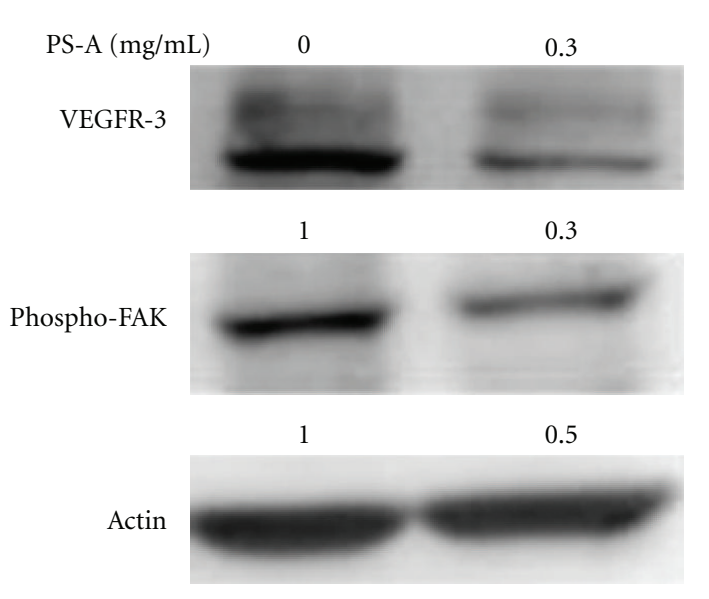

(a)
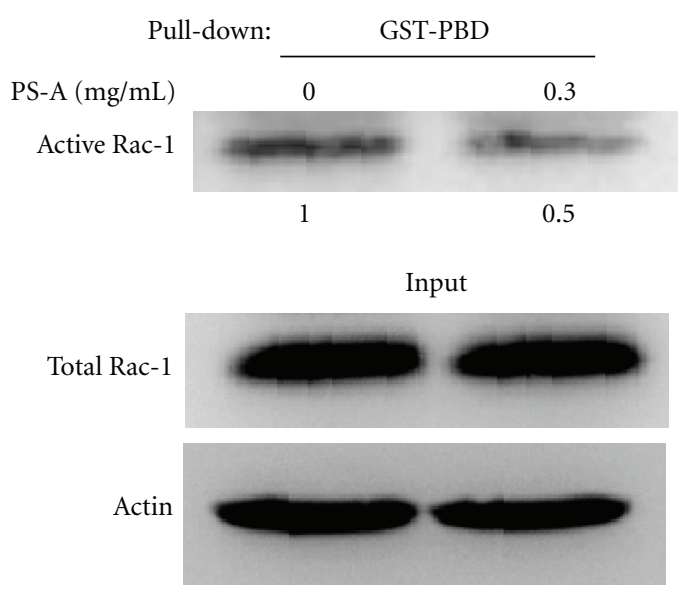

(b)

Figure 4: Suppression of VEGFR-3/FAK/Rac-1 signaling by PS-A. (a) After serum starvation for $24 \mathrm{~h}$, $786 \mathrm{O}$ cells were treated with or without $0.3 \mathrm{mg} / \mathrm{mL}$ of PS-A for $24 \mathrm{~h}$, and the lysates were analyzed by Western blot analysis to detect the expression levels of VEGFR-3 and the phosphorylated status of FAK. Actin was used as the loading control. The intensities of bands were quantitated and normalized to actin levels. (b) After serum starvation for $24 \mathrm{~h}, 786 \mathrm{O}$ cells were treated with or without $0.3 \mathrm{mg} / \mathrm{mL}$ of PS-A for $12 \mathrm{~h}$, and the lysates were incubated with GST-PBD beads to examine the levels of GTP-bound Rac-1 (upper). The levels of total Rac-1 and actin in total lysates were analyzed by Western blotting (lower).

(Figure 4(a)). It has been shown that VEGFRs are involved in the activation of FAK [28]. Therefore, we examined the phosphorylated status of FAK in RCC cells treated with PS-A. The results revealed that the phosphorylation of FAK in PSA-treated 7860 cells was remarkably reduced as compared with that of control cells (Figure 4(a)). Recent reports have shown that phosphorylated FAK is capable of promoting the activation of Rac-1 [29]. To investigate the effects of PSA on activation of Rac-1, GST-PBD fusion proteins were purified to perform pull-down assay. GTP-bound Rac-1 of $786 \mathrm{O}$ cells was significantly decreased by treating with PS$\mathrm{A}$ as demonstrated by pull-down assay, revealing that PS-A reduces the activation of Rac-1 (Figure 4(b)). These results indicate that PS-A suppresses cancer cell migration by inhibiting VEGFR-3/FAK/Rac-1 signaling pathway.

3.4. PS-A Reduces the Formation of Actin Filaments of RCC Cells. Recent studies demonstrated that Rac-1 has been reported to be a modulator of cytoskeletal dynamics to affect cell migration [30], and the dynamic change of actin cytoskeleton plays an essential role in cell mobility and migration [31]. Therefore, the effects of PS-A on the formation of actin filaments were studied by staining with phalloidin. The results revealed that PS-A markedly decreased actin filament formation as shown by confocal microscope analysis (Figure 5(a)). The ratio of F-actin to G-actin in PS-A-treated $786 \mathrm{O}$ cells was significantly reduced as compared with that of control cells (Figure 5(b)). These results indicate that PSA disrupts the polymerization of actin filaments to inhibit the migration of RCC cells.

\section{Discussion}

Many studies demonstrated the anticancer activities of Chinese herb medicines in leukemia, colorectal carcinoma, gastric cancer, breast cancer, and prostate cancer [32-36]. Therefore, Chinese herb medicines have been considered as the alternative medicine to treat many tumors which are resistant to traditional cancer therapies. In this study, ten kinds of potential Chinese herb medicines were screened and the aqueous extracts of Paeonia suffruticosa exhibited a higher antiproliferation activity to RCC cells. Previous studies showed that Paeonia suffruticosa inhibits proliferation in human malignancies including liver cancer $[7,13]$, esophageal cancer [11,37], and lung cancer cell lines [14]. Therefore, Paeonia suffruticosa could be considered as a potential adjuvant therapy to enhance the efficacy of chemotherapy for patients with aggressive RCC.

VEGFR-3 belongs to the family of receptor tyrosine kinase and is able to activate FAK/Rac-1 pathway [28, 38, 39]. Garces et al. have demonstrated that the NH2-terminus of VEGFR-3 is associated with the $\mathrm{COOH}$ terminus of FAK, and disruption of VEGFR3/FAK interaction results in the dissociation of FAK from the focal adhesions [28]. The expression of VEGFR- 3 has been found to be upregulated in various human malignancies, including leukemia, breast cancer, colorectal cancer, prostate cancer, renal cell carcinoma, and hepatocellular carcinoma $[38,40]$. Expression levels of VEGFR3 are correlated with portal vein invasion, tumor recurrence, and shorter disease-free survival in HCC patients [41, 42]. It has been shown that the activation of VEGFR-3 participates in cell proliferation, migration, and survival [43]. This study demonstrated that PS-A at the concentration of $\mathrm{IC}_{50}$ migration markedly reduces VEGFR-3 expression and inhibits the activation of VEGFR-3 signaling, indicating that PS-A may have the potential to prevent the progression of human malignancies.

The invasion of cancer cells into adjacent tissues is a critical step in the process of tumor metastasis [44]. Developing of the migratory capacity plays an essential role in 


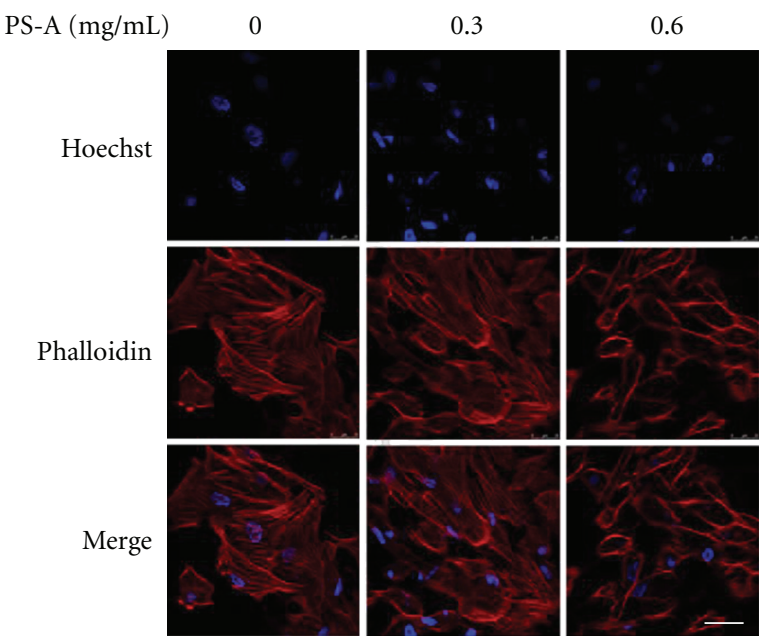

(a)
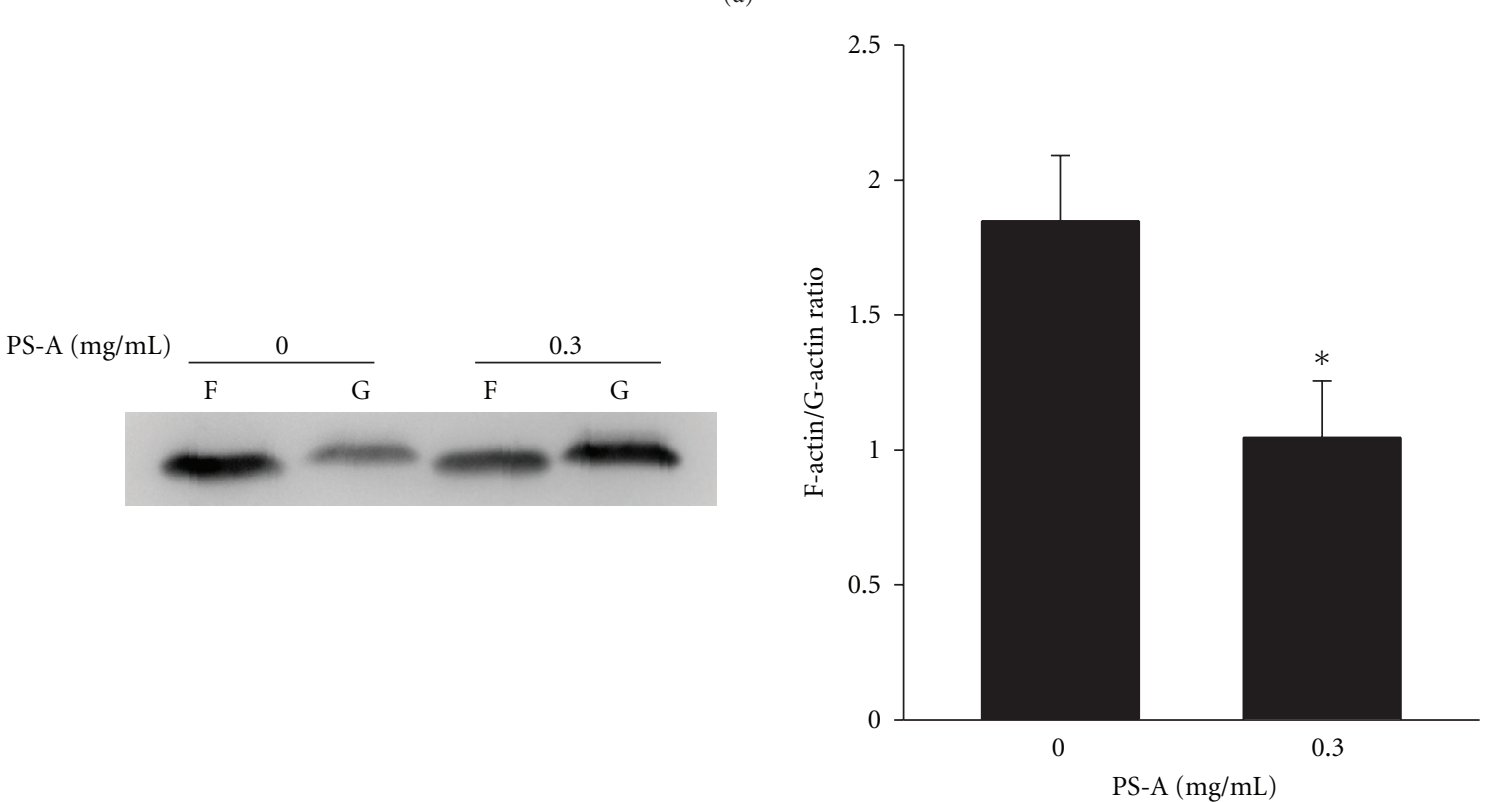

(b)

FIGURE 5: Disruption of actin filament formation by PS-A in RCC cells. (a) $2 \times 10^{5}$ of $786 \mathrm{O}$ cells were treated with 0 , 0.3 , and $0.6 \mathrm{mg} / \mathrm{mL}$ of PS-A for $12 \mathrm{~h}$. After fixation, cells were stained with Alexa568-phalloidin (red) and Hoechst 33258 (blue). Fluorescent images were taken with a Leica TCS SP5 Spectral Confocal System. Bars, $20 \mu \mathrm{m}$. (b) $2 \times 10^{5}$ of $786 \mathrm{O}$ cells were treated with or without $0.3 \mathrm{mg} / \mathrm{mL}$ of PS-A, and the fractions containing F- or G-actin were separated and then subjected to Western blotting using actin antibody. The intensities of bands were quantitated, and the ratio of $\mathrm{F}$-actin to $\mathrm{G}$-actin was calculated. The data are represented as the means $\pm \mathrm{SD}(n=3)$. ${ }^{*} P<0.05$ compared with untreated cells.

cancer cell invasiveness [31]. In this investigation, we demonstrate that PS-A exhibits strong inhibitory effects on the migration, invasion, and metastasis of RCC cells. It might be achieved by disrupting the polymerization of actin filaments, which is tightly regulated during cell migration [45]. Previous studies suggested that the motility of cancer cells is mainly managed by the Rho family of GTPases [46]. Our results showed that the activity of Rac-1, one member of the Rho family, was suppressed by PS-A in RCC cells, indicating the potential mechanism for the inhibitory effects of PS-A to cancer cell migration.
In conclusion, this research demonstrates that PS-A is able to prohibit tumor growth and metastasis through disrupting the formation of actin filament and impairing the signaling pathway of VEGFR-3. The present results elucidate anticancer mechanism of PS-A and suggest that PS-A is a potential therapeutic or adjuvant strategy for the treatment of RCC patients.

\section{Conflict of Interests}

The authors declare that there is no conflict of interests. 


\section{Acknowledgments}

This work was supported by the Grant DOH-98-TD-I-111TM020 from National Science and Technology Plan, Department of Health, Taiwan. S.-C. Wang and S.-W. Tang equally contributed to this work.

\section{References}

[1] M. Markman, "Safety issues in using complementary and alternative medicine," Journal of Clinical Oncology, vol. 20, no. 18, pp. 39S-41S, 2002.

[2] Y. Cui, X. O. Shu, Y. Gao et al., "Use of complementary and alternative medicine by Chinese women with breast cancer," Breast Cancer Research and Treatment, vol. 85, no. 3, pp. 263270, 2004.

[3] M. A. Richardson, T. Sanders, J. L. Palmer, A. Greisinger, and S. E. Singletary, "Complementary/alternative medicine use in a comprehensive cancer center and the implications for oncology," Journal of Clinical Oncology, vol. 18, no. 13, pp. 25052514, 2000.

[4] H. C. Lin, H. Y. Ding, and Y. C. Wu, "Two novel compounds from Paeonia suffruticosa," Journal of Natural Products, vol. 61, no. 3, pp. 343-346, 1998.

[5] C. L. Hsieh, C. Y. Cheng, T. H. Tsai et al., "Paeonol reduced cerebral infarction involving the superoxide anion and microglia activation in ischemia-reperfusion injured rats," Journal of Ethnopharmacology, vol. 106, no. 2, pp. 208-215, 2006.

[6] Y. Li, W. Zhang, L. Huang, and J. Shi, "Pharmacological of cortex moutan and core," Zhongguo Zhong Yao Za Zhi, vol. 22, no. 4, pp. 214-254, 1997.

[7] G. S. Oh, H. O. Pae, H. Oh et al., "In vitro anti-proliferative effect of 1,2,3,4,6-penta-O-galloyl-beta-D-glucose on human hepatocellular carcinoma cell line, SK-HEP-1 cells," Cancer Letters, vol. 174, no. 1, pp. 17-24, 2001.

[8] M. P. Sheehan and D. J. Atherton, "One-year follow up of children treated with Chinese medicinal herbs for atopic eczema," British Journal of Dermatology, vol. 130, no. 4, pp. 488-493, 1994.

[9] T. Okubo, F. Nagai, T. Seto, K. Satoh, K. Ushiyama, and I. Kano, "The inhibition of phenylhydroquinone-induced oxidative DNA cleavage by constituents of Moutan Cortex and Paeoniae Radix," Biological and Pharmaceutical Bulletin, vol. 23, no. 2, pp. 199-203, 2000.

[10] C. H. Lau, C. M. Chan, Y. W. Chan et al., "Pharmacological investigations of the anti-diabetic effect of Cortex Moutan and its active component paeonol," Phytomedicine, vol. 14, no. 11, pp. 778-784, 2007.

[11] G. P. Sun, X. Wan, S. P. Xu, H. Wang, S. H. Liu, and Z. G. Wang, "Antiproliferation and apoptosis induction of paeonol in human esophageal cancer cell lines," Diseases of the Esophagus, vol. 21, no. 8, pp. 723-729, 2008.

[12] Y. Sun, Y. Dong, H. J. Jiang et al., "Dissection of the role of paeoniflorin in the traditional Chinese medicinal formula Si-NiSan against contact dermatitis in mice," Life Sciences, vol. 84, no. 11-12, pp. 337-344, 2009.

[13] S. P. Xu, G. P. Sun, Y. X. Shen, W. Wei, W. R. Peng, and H. Wang, "Antiproliferation and apoptosis induction of paenol in HepG2 cells," World Journal of Gastroenterology, vol. 13, no. 2, pp. 250-256, 2007.
[14] J. Y. Hung, C. J. Yang, Y. M. Tsai, H. W. Huang, and M. S. Huang, "Antiproliferative activity of paeoniflorin is through cell cycle arrest and the Fas/Fas ligand-mediated apoptotic pathway in human non-small cell lung cancer A549 cells," Clinical and Experimental Pharmacology and Physiology, vol. 35, no. 2, pp. 141-147, 2008.

[15] A. J. Pantuck, A. Zisman, and A. Belldegrun, "The changing natural history of renal cell carcinoma," Journal of Urology, vol. 166, pp. 1611-1623, 2001.

[16] P. Russo, "Renal cell carcinoma: presentation, staging, and surgical treatment," Seminars in Oncology, vol. 27, no. 2, pp. 160$176,2000$.

[17] C. P. Pavlovich and L. S. Schmidt, "Searching for the hereditary causes of renal-cell carcinoma," Nature Reviews Cancer, vol. 4, no. 5, pp. 381-393, 2004.

[18] J. C. Cheville, C. M. Lohse, H. Zincke, A. L. Weaver, and M. L. Blute, "Comparisons of outcome and prognostic features among histologic subtypes of renal cell carcinoma," American Journal of Surgical Pathology, vol. 27, no. 5, pp. 612-624, 2003.

[19] R. J. Amato, "Chemotherapy for renal cell carcinoma," Seminars in Oncology, vol. 27, no. 2, pp. 177-186, 2000.

[20] B. R. Lane, B. I. Rini, A. C. Novick, and S. C. Campbell, "Targeted molecular therapy for renal cell carcinoma," Urology, vol. 69, no. 1, pp. 3-10, 2007.

[21] D. J. Van Spronsen, K. J. M. De Weijer, P. F. A. Mulders, and P. H. M. De Mulder, "Novel treatment strategies in clear-cell metastatic renal cell carcinoma," Anti-Cancer Drugs, vol. 16, no. 7, pp. 709-717, 2005.

[22] T. Ishimura, I. Sakai, I. Hara, H. Eto, and H. Miyake, "Microscopic venous invasion in renal cell carcinoma as a predictor of recurrence after radical surgery," International Journal of Uro$\log y$, vol. 11, no. 5, pp. 264-268, 2004.

[23] M. S. Ernstoff, T. S. Crocenzi, J. D. Seigne et al., "Developing a rational tumor vaccine therapy for renal cell carcinoma: immune Yin and Yang," Clinical Cancer Research, vol. 13, no. 2, pp. 733ss-740s, 2007.

[24] J. A. Glaspy, "Therapeutic options in the management of renal cell carcinoma," Seminars in Oncology, vol. 29, no. 3, pp. 4146, 2002.

[25] E. Corey, L. G. Brown, J. E. Quinn et al., "Zoledronic acid exhibits inhibitory effects on osteoblastic and osteolytic metastases of prostate cancer," Clinical Cancer Research, vol. 9, no. 1, pp. 295-306, 2003.

[26] G. Chen, P. Raman, P. Bhonagiri, A. B. Strawbridge, G. R. Pattar, and J. S. Elmendorf, "Protective effect of phosphatidylinositol 4,5-bisphosphate against cortical filamentous actin loss and insulin resistance induced by sustained exposure of 3T3L1 adipocytes to insulin," Journal of Biological Chemistry, vol. 279, no. 38, pp. 39705-39709, 2004.

[27] M. J. Cross, J. Dixelius, T. Matsumoto, and L. Claesson-Welsh, "VEGF-receptor signal transduction," Trends in Biochemical Sciences, vol. 28, no. 9, pp. 488-494, 2003.

[28] C. A. Garces, E. V. Kurenova, V. M. Golubovskaya, and W. G. Cance, "Vascular endothelial growth factor receptor-3 and focal adhesion kinase bind and suppress apoptosis in breast cancer cells," Cancer Research, vol. 66, no. 3, pp. 1446-1454, 2006.

[29] D. P. Choma, V. Milano, K. M. Pumiglia, and C. M. DiPersio, "Integrin $\alpha 3 \beta 1$-dependent activation of FAK/Src regulates Rac1-mediated keratinocyte polarization on laminin-5," Journal of Investigative Dermatology, vol. 127, no. 1, pp. 31-40, 2007. 
[30] S. J. Heasman and A. J. Ridley, "Mammalian Rho GTPases: new insights into their functions from in vivo studies," Nature Reviews Molecular Cell Biology, vol. 9, no. 9, pp. 690-701, 2008.

[31] D. Vignjevic and G. Montagnac, "Reorganisation of the dendritic actin network during cancer cell migration and invasion," Seminars in Cancer Biology, vol. 18, no. 1, pp. 12-22, 2008.

[32] Y. Y. Cha, E. O. Lee, H. J. Lee et al., "Methylene chloride fraction of Scutellaria barbata induces apoptosis in human U937 leukemia cells via the mitochondrial signaling pathway," Clinica Chimica Acta, vol. 348, no. 1-2, pp. 41-48, 2004.

[33] Q. Chen, W. Peng, S. Qi, and A. Xu, "Apoptosis of human highly metastatic lung cancer cell line 95-D induced by acutiaporberine, a novel bisalkaloid derived from Thalictrum acutifolium," Planta Medica, vol. 68, no. 6, pp. 550-553, 2002.

[34] T. C. Hsieh, X. Lu, J. Guo et al., "Effects of herbal preparation Equiguard on hormone-responsive and hormone-refractory prostate carcinoma cells: mechanistic studies," International Journal of Oncology, vol. 20, no. 4, pp. 681-689, 2002.

[35] S. Y. Lin, J. D. Liu, H. C. Chang, S. D. Yeh, C. H. Lin, and W. S. Lee, "Magnolol suppresses proliferation of cultured human colon and liver cancer cells by inhibiting DNA synthesis and activating apoptosis," Journal of Cellular Biochemistry, vol. 84, no. 3, pp. 532-544, 2002.

[36] J. Ma, N. Y. Fu, D. B. Pang, W. Y. Wu, and A. L. Xu, "Apoptosis induced by isoliquiritigenin in human gastric cancer MGC803 cells," Planta Medica, vol. 67, no. 8, pp. 754-757, 2001.

[37] X. A. Wan, G. P. Sun, H. Wang, S. P. Xu, Z. G. Wang, and S. H. Liu, "Synergistic effect of paeonol and cisplatin on oesophageal cancer cell lines," Digestive and Liver Disease, vol. 40, no. 7, pp. 531-539, 2008.

[38] J. L. Su, C. J. Yen, P. S. Chen et al., "The role of the VEGFC/VEGFR-3 axis in cancer progression," British Journal of Cancer, vol. 96, no. 4, pp. 541-545, 2007.

[39] Y. Wang, M. Nakayama, M. E. Pitulescu et al., "Ephrin-B2 controls VEGF-induced angiogenesis and lymphangiogenesis," Nature, vol. 465, no. 7297, pp. 483-486, 2010.

[40] H. Bando, M. Brokelmann, M. Toi et al., "Immunodetection and quantification of vascular endothelial growth factor receptor-3 in human malignant tumor tissues," International Journal of Cancer, vol. 111, no. 2, pp. 184-191, 2004.

[41] Z. Lian, J. Liu, M. Wu et al., "Hepatitis B x antigen up-regulates vascular endothelial growth factor receptor 3 in hepatocarcinogenesis," Hepatology, vol. 45, no. 6, pp. 1390-1399, 2007.

[42] D. K. Dhar, H. Naora, A. Yamanoi et al., "Requisite role of VEGF receptors in angiogenesis of hepatocellular carcinoma: a comparison with angiopoietin/Tie pathway," Anticancer Research, vol. 22, no. 1 A, pp. 379-386, 2002.

[43] A. Salameh, F. Galvagni, M. Bardelli, F. Bussolino, and S. Oliviero, "Direct recruitment of CRK and GRB2 to VEGFR3 induces proliferation, migration, and survival of endothelial cells through the activation of ERK, AKT, and JNK pathways," Blood, vol. 106, no. 10, pp. 3423-3431, 2005.

[44] A. Besson, R. K. Assoian, and J. M. Roberts, "Regulation of the cytoskeleton: an oncogenic function for CDK inhibitors?" $\mathrm{Na}$ ture Reviews Cancer, vol. 4, no. 12, pp. 948-955, 2004.

[45] A. J. Ridley, M. A. Schwartz, K. Burridge et al., "Cell migration: integrating signals from front to back," Science, vol. 302, no. 5651, pp. 1704-1709, 2003.

[46] A. Hall, "Rho GTpases and the actin cytoskeleton," Science, vol. 279, no. 5350, pp. 509-514, 1998. 


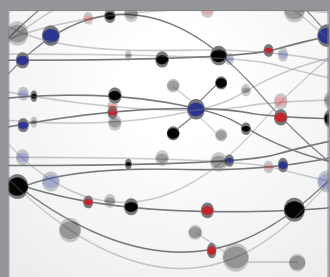

The Scientific World Journal
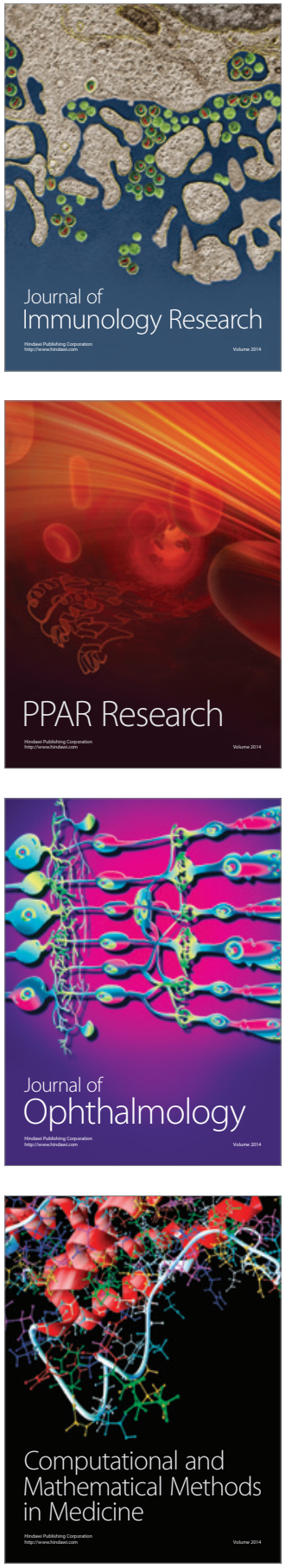

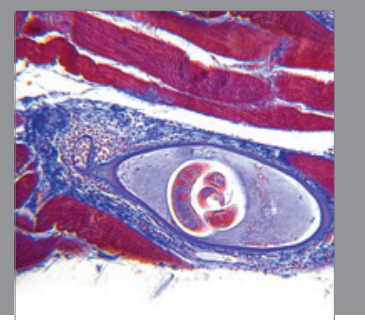

Gastroenterology

Research and Practice
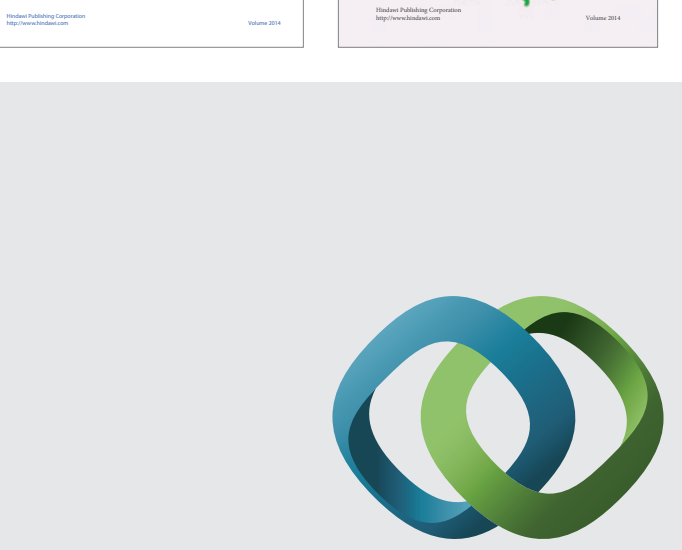

\section{Hindawi}

Submit your manuscripts at

http://www.hindawi.com
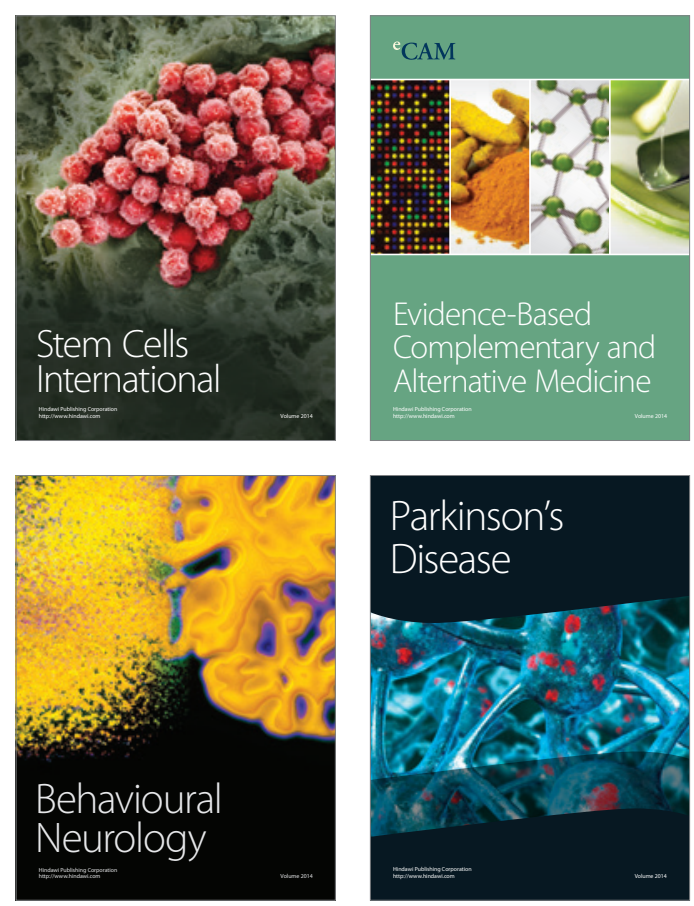

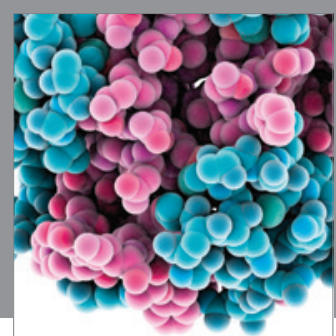

Journal of
Diabetes Research

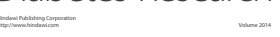

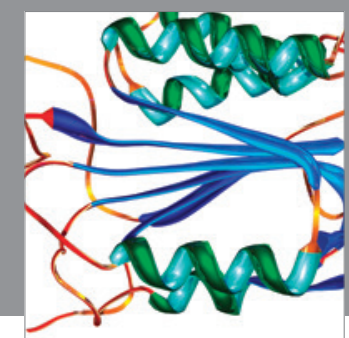

Disease Markers
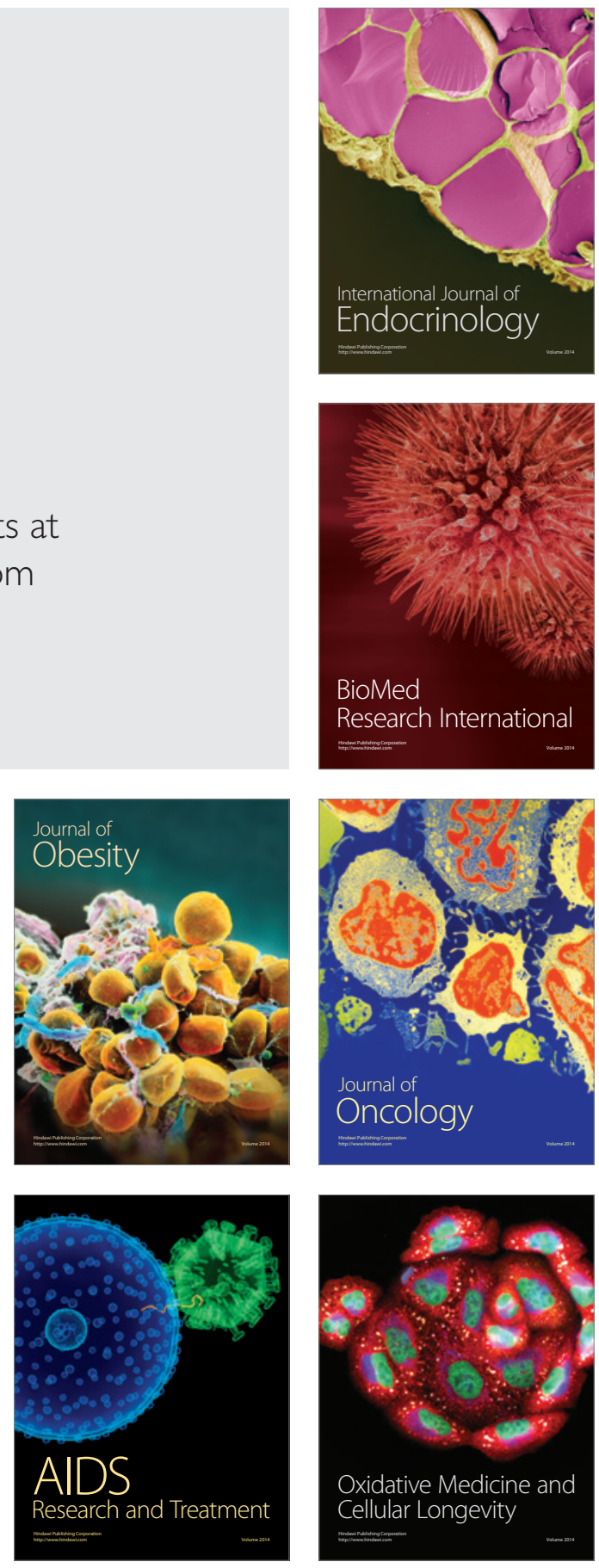